\title{
Platinum and Palladium complexes of Fluorenyl Porphyrins as Red Phosphors for Light-Emitting Devices
}

\author{
Samuel Drouet, ${ }^{\mathrm{a}}$ Christine O. Paul-Roth, ${ }^{\mathrm{a}, \mathrm{b}^{*}}$ Valeria Fattori, ${ }^{\mathrm{c}}$ \\ Massimo Cocchi, ${ }^{\mathrm{c}}$ and J. A. Gareth Williams, ${ }^{\mathrm{d}}$
}

a'Université Européenne de Bretagne, Sciences Chimiques de Rennes, SCR-UMR-6226,

${ }^{\mathrm{b}}$ Université Européenne de Bretagne, INSA-SCR- UMR 6226

Université de Rennes I, 35042 Rennes Cedex, France

${ }^{\mathrm{c}}$ Consiglio Nazionale delle Ricerche (CNR)

Istituto per la Sintesi Organica e la Fotoreattività (ISOF)

via Gobetti 101, 40129 Bologna (Italy)

${ }^{\mathrm{d}}$ Department of Chemistry, University of Durham, Durham DH1 3LE, UK

*Corresponding author. Fax: 022323 56 37; Tel.: 0223236372

e-mail: christine.paul@univ-rennes1.fr or christine.paul@insa-rennes.fr

Platinum(II) and palladium(II) complexes of a porphyrin with fluorenyl groups linked directly at the meso-positions (TFP) have been synthesized and characterized. Their luminescence properties in solution have been studied under ambient conditions and at $77 \mathrm{~K}$. Compared to the corresponding complexes of tetraphenylporphyrin TPP, the emission is red-shifted in both cases. Radiative rate constants are found to be enhanced by the fluorenyl substituents, although non-radiative decay rates are also increased in solution. Short-wavelength UV excitation leads to no detectable fluorenylbased fluorescence, indicating that very efficient transfer of energy to the porphyrin occurs. An OLED in which PtTFP is used as a red phosphor has been prepared and its electroluminescence performance assessed. High current "roll-off" is significantly delayed to higher currents compared to previously described OLEDs that make use of standard platinum porphyrins as emitters, an effect which can be attributed to the shorter radiative lifetime of PtTFP.

\section{Introduction}

For potential application in large-area flat-panel displays, ${ }^{1}$ organic light-emitting diodes (OLEDs) are attracting vast scientific and industrial attention. ${ }^{2}$ Organic materials for green and blue OLEDs exhibiting high-intensity luminescence have been developed over recent years. ${ }^{3-6}$ Polyfluorenes are leading candidates for blue OLEDs ${ }^{7}$ and are expected to be part of future full-color polymerbased displays. Corresponding materials for red electroluminescence (EL) remain relatively rare, since luminescence efficiencies tend to decrease with decreasing excited state energy, ${ }^{8}$ as the rate of vibronic non-radiative decay increases. Red light emission is typically achieved by doping red dyes, such as porphyrins, into host materials with a larger energy gap. ${ }^{9}$ Thus, a conjugated 
polymer, poly(9,9-dioctylfluorene), doped with a tetraphenylporphyrin molecule dispersed in a host matrix, has been used as a light-emitting diode. ${ }^{10}$ A series of star-shaped porphyrins bearing pendant oligofluorene arms, recently reported by Bo et al., have also been investigated for this purpose. ${ }^{11,12}$

We have previously reported the synthesis of a free-base porphyrin possessing four pendant fluorene arms at the meso-positions, in a study initially directed at the catalytic properties of its ruthenium(II) complex. ${ }^{13-16}$ More recently, we discussed how the presence of the fluorenyl substituent serves to raise the quantum yield of fluorescence of the porphyrin. ${ }^{17-19}$ These results contrast with those obtained with a related porphyrin carrying a total of eight ${ }^{20}$ or sixteen ${ }^{21}$ fluorenyl pendant arms, two or four respectively, at each of the meso-positions, connected to the porphyrin ring via an interposed 3,5-substituted benzene ring. In these cases, the central porphyrin behaves like tetraphenylporphyrin (TPP), with the peripheral fluorene moieties acting as photonharvesting units which transfer some of their absorbed energy to the porphyrin.

It has long been recognised that the efficiency of an OLED can potentially be increased if the normally non-emissive triplet states that are statistically formed in a 3:1 excess over the singlet states can be harnessed and made to emit light too. Complexes of $3^{\text {rd }}$ row transition metals have been found to be successful for this purpose owing to their high spin-orbit coupling constants, which promote triplet radiative decay. ${ }^{22}$ Red-emitting platinum complexes of octa-alkylporphyrins were amongst the first compounds to be tested for such applications. ${ }^{9}$ Despite their rather long luminescence lifetimes of around 60-80 $\mu \mathrm{s}$, which makes them susceptible to undesirable efficiency-limiting processes such as triplet-triplet annihilation, they have continued to attract interest. Such disadvantages are partly compensated by advantages such as the narrowness of their emission bands around $650 \mathrm{~nm}$, which lead to high colour purity red. Some recent studies have combined platinum porphyrins with fluorenes. For example, in 2006, Anzenbacher showed that OLED materials composed of $\mathrm{Alq}_{3}-$ oligofluorene- $\mathrm{Pt}(\mathrm{II})$ porphyrin triads $\left\{\mathrm{Alq}_{3}=\right.$ aluminium tris $(8-$ quinolinol) $\}$ have high color purity emission (CIE $x, y=0.706,0.277$ ), almost identical to the photoluminescence from thin films in polystyrene. ${ }^{23}$ These systems comprise 5-(fluoren-2-yl)10,15,20-tris(4-tolyl)porphyrin. Given the increased radiative rate constant and increased quantum yield that we observed for tetrakis(fluoren-2-yl)porphyrin (TFP) compared to tetraphenylporphyrin $(\mathrm{TPP})\left(k_{\mathrm{r}}=3.0 \times 10^{7}\right.$ and $1.5 \times 10^{7} \mathrm{~s}^{-1} ; \Phi_{\mathrm{f}}=0.24$ and 0.13 respectively $),{ }^{16}$ we reasoned that it would be of interest to prepare the platinum porphyrin of TFP and to explore its performance in an OLED. For example, if the triplet radiative rate constant were to be similarly increased, this could help to counter the aforementioned drawback of the metalloporphyrins.

In this work, we report on the synthesis and photophysics of the platinum(II) complex of TFP, and compare its emission properties to those of PtTPP. The corresponding palladium complexes 
have also been prepared, in order to provide further information on the influence of the fluorenyl substitution on the excited state behaviour of this class of metalloporphyrins. ${ }^{24}$ An OLED has been fabricated using PtTFP as a red phosphor, giving a maximum brightness of $40 \mathrm{~cd} / \mathrm{m}^{2}$ and a maximum external quantum efficiency of $6 \%$ with slow roll-off. The electroluminescence emission is located in the red-purple region of the visible spectrum. These values - obtained in a very simple two layer device - seem to locate PtTFP in an encouraging position compared to other red emitters of the same type. ${ }^{6}$

\section{Results and Discussion}

\section{Porphyrin metallation and ${ }^{1} \mathbf{H}$ NMR}

Platinum and palladium insertion into the porphyrin ring was accompanied by distinctive changes in the ${ }^{1} \mathrm{H}$ NMR. These insertions result in all ${ }^{1} \mathrm{H}$ resonances exhibiting a small shift to lower frequency compared with the free-base porphyrin (e.g., TFP shows a singlet at $\delta=8.98 \mathrm{ppm}$ for the eight pyrrolic H atoms, ${ }^{13}$ which shifts to $\delta=8.88$ and $8.93 \mathrm{ppm}$ for the corresponding $\mathrm{Pt}(\mathrm{II})$ and $\mathrm{Pd}(\mathrm{II})$ complexes). ${ }^{1} \mathrm{H}$ NMR shifts upon metallation of porphyrins are typically small and may be either upfield or downfield depending upon the metal; the slight upfield ${ }^{1} \mathrm{H}$ chemical shift for platinum and palladium porphyrins is attributed to metal-to-porphyrin $\pi$-backbonding. ${ }^{25}$

\section{Photophysical properties of platinum(II) porphyrins in solution and in dilute frozen glasses}

The absorption and emission data for the new compounds reported here, PtTFP and PdTFP, together with corresponding data recorded by us under the same conditions for the $\mathrm{Pt}$ and $\mathrm{Pd}$ porphyrins of TPP, are summarised in Table 1. We first consider the two Pt porphyrins. The absorption spectrum of PtTFP is similar to that of the model compound (Figure 1). The main differences in the visible region are a small shift of the Soret band to the red, an even smaller shift of the $\mathrm{Q}$ bands, and a slight decrease in the intensity ratio between the two $\mathrm{Q}$ bands. Absorption by the fluorenyl units accounts for the enhanced absorption around $300 \mathrm{~nm}$.

(Insert Table 1 here please)

(Insert Fig. 1 here please) 
Excitation either in the UV or into the Soret bands leads to characteristic triplet emission from the metalloporphyrin in all cases. The emission spectra in $\mathrm{CH}_{2} \mathrm{Cl}_{2}$ at $298 \mathrm{~K}$ reveal two bands for each compound (Figure 2). The introduction of the fluorenyl units is seen to shift the emission of PtTFP to the red by around $10 \mathrm{~nm}$ compared to PtTPP. These small red-shifts in absorption and emission mirror the behaviour that we previously observed for the corresponding free base porphyrins. ${ }^{19}$ The small stabilisation of the lowest-energy ${ }^{1} \pi-\pi^{*}$ and ${ }^{3} \pi-\pi *$ excited states upon moving from phenyl to fluorenyl substituents is likely to be associated with the so-called in-plane nuclear reorganization (INPR), whereby the more conjugated substituent draws the meso-carbon $\left(C_{m}\right)$ away from the porphyrin core, leading to a contracted $C_{\alpha} C_{m} C_{\alpha}$ angle $\left(C_{\alpha}=\right.$ pyrrolic 2 -carbon $){ }^{26}$ This effect, which has been shown by TD-DFT calculations to increase the HOMO energy with little effect on the LUMO ${ }^{27}$ is now regarded to be more significant than any small deviation of the porphyrin ring from planarity induced by the substituent, at least for sterically unencumbered substituents.

The lifetime of the phosphorescence is noticeably shorter for PtTFP ( $22 \mu \mathrm{s})$ than for PtTPP (59 $\mu$ s). This reduction in lifetime is accompanied by a decrease in the quantum yield. Assuming that the triplet emissive state is formed with approximately unitary efficiency upon light absorption (a reasonable assumption given the very fast $\mathrm{S} \rightarrow \mathrm{T}$ intersystem crossing expected to arise from the presence of the Pt ion), we can estimate the radiative $\left(k_{\mathrm{r}}\right)$ and non-radiative $\left(\Sigma k_{\mathrm{nr}}\right)$ decay constants as follows :

$$
k_{\mathrm{r}}=\Phi / \tau \text { and } k_{\mathrm{nr}}=1 / \tau-k_{\mathrm{r}}
$$

The values so obtained are summarised in Table 1, and indicate that $k_{\mathrm{r}}$ is indeed increased in the fluorenyl porphyrin TFP compared to TPP, in line with the effect we observed previously on the radiative decay of the singlet state for the corresponding free-base porphyrins. ${ }^{19}$ However, in the present instance, this beneficial effect is apparently partially offset by an increase in non-radiative decay in solution, which results in a net lowering of the phosphorescence quantum yield, at least under these conditions. In a frozen glass at $77 \mathrm{~K}$ (spectra are shown in Figure 3), the lifetime of PtTFP is $102 \mu$ s compared to $132 \mu$ s for PtTPP, which would be consistent with a modest increase in $k_{\mathrm{r}}$, assuming that non-radiative pathways are comparable for the two systems under these rigid conditions.

(Insert Fig. 2-3 here please) 


\section{Photophysical properties of palladium(II) porphyrins}

The absorption spectra of the palladium(II) complexes of TFP and TPP are shown in Figure 4. Again, a small red-shift is observed in the Soret band upon introduction of the fluorenyl substituents, whilst the energy of the Q bands is affected to an even smaller extent. The enhanced absorption arising from the fluorenyl groups is again evident in the UV region $<330 \mathrm{~nm}$.

The palladium(II) porphyrins also emit in degassed solution at room temperature (Table 1 and Figure 5). Their emission is red-shifted compared to the platinum analogues and, again, that of TFP is at slightly lower energy than the corresponding TPP compound. The luminescence lifetimes are an order of magnitude longer than for the Pt derivatives, both in solution at room temperature and in a glass at $77 \mathrm{~K}$. Such a long lifetime at room temperature clearly renders the palladium complex inappropriate as an OLED emitter, since triplet-triplet quenching and saturation of the available dopant excited states become severe problems for emitters having lifetimes of this magnitude. On the other hand, such long lifetimes can be of interest for oxygen-sensing systems. ${ }^{28}$

(Insert Fig. 4-5 here please)

\section{Solid state photoluminescence and electroluminescence}

Solid state photoluminescence (PL) and electroluminescence (EL) investigations have been performed on PtTFP as the most promising phosphorescent emitter in an electroluminescent device.

$$
\text { (Insert Fig. } 6 \text { here please) }
$$

Excitation and emission spectra have been measured on a film (70 nm thick) comprised of TPD doped with PtTFP, 5\% by weight (Figure 6). TPD, a good amorphous film-forming and good hole-transport material, has been chosen as the host for PtTFP because its emission, peaked in the range 400- 
$420 \mathrm{~nm}$, matches very well the strong Soret absorption band of the guest, which should favour efficient energy transfer to the porphyrin. In fact, the TPD doped film shows only the red emission of the guest when excited in the host's absorption band, proving an efficient energy transfer from the host to the guest. The emission peak of $668 \mathrm{~nm}$ is blue-shifted by $10 \mathrm{~nm}$ compared to the room temperature solution value and much more similar to the $77 \mathrm{~K}$ one (see Table 1). This presumably reflects the greater rigidity of the environment, which may partially inhibit the conjugation of the fluorenyl and porphyrinic units in the excited state. The PL yield measured in argon atmosphere was $0.20 \pm 0.05$, a value which is 10 times greater than the solution one. Clearly, the molecule stiffening in the rigid solid matrix slows down the non-radiative decay.

The EL test was performed on a simple two-layer OLED structure similar to our previously reported paper on the well-studied PtOEP. ${ }^{29}$ In this device, the first layer has to perform both hole transport and emission. TPD was selected as a host material for PtTFP in this first layer. Not only is it an effective and widely-used hole transporting material, but it also offers efficient energy transfer to the phosphorescent guest, as demonstrated by the photoluminescence measurements reported above. Moreover, the energy of the PtTFP triplet, which can be estimated to be $1.80 \mathrm{eV}$ from the high energy maximum in the emission spectrum, is sufficiently low with respect to the host triplet energy (2.4 eV) to prevent back energy transfer. ${ }^{30}$ This latter effect is frequently extremely important as a cause of strong quenching of the EL, which is mostly determined by triplet state kinetics. The second layer of TAZ acts as an electron transporting/hole blocking layer, and has a sufficiently high triplet energy (2.75 eV) to avoid PtTFP excitons from being quenched at the layer interface.

\section{(Insert Fig. 7 here please)}

The electroluminescence behaviour of the OLED is reported in Figure 7. External quantum efficiency reaches a maximum value of 6\% at $1 \times 10^{-3} \mathrm{~mA} / \mathrm{cm}^{2}(10 \mathrm{~V})$, indicating that the recombination probability must be close to unity, if it is borne in mind that the light-guide effect attenuates by a factor of four the light coming out frontally from the device. The EL quantum efficiency shows the typical roll-off at high currents due to excitonexciton and/or exciton/charge interaction and to high field induced exciton dissociation. ${ }^{31}$ Nevertheless, the efficiency remains in excess of $5 \%$ for a wide range of current (voltage) values: from $1 \times 10^{-4} \mathrm{~mA} / \mathrm{cm}^{2}(8 \mathrm{~V})$ to $1 \times 10^{-1} \mathrm{~mA} / \mathrm{cm}^{2}(14 \mathrm{~V})$. In the same current range, quantum efficiency drops off an order of magnitude when other Pt-porphyrins have been employed as the emitting dopants. ${ }^{32,33}$ Clearly, the shorter luminescence lifetime of the new PtTFP compared to other previously-studied Pt-porphyrins (e.g., lifetimes in solid matrix are reported to be $73-110 \mu$ s for PtOEP 30,33 and $44 \mu \mathrm{s}$ 
for PtTPP ${ }^{23}$ ) ensures that there is a lower probability of the excited state being quenched by the exciton-exciton and exciton-charge interactions. Although the maximum brightness of $40 \mathrm{~cd} / \mathrm{m}^{2}$ achieved is apparently less than, for example, the value of $100 \mathrm{~cd} / \mathrm{m}^{2} \mathrm{reported} \mathrm{for} \mathrm{PtOEP}$, it should be noted that this photometric (as opposed to radiometric) measurement of brightness factors in the eye's sensitivity, which falls to zero beyond $700 \mathrm{~nm}$. The lower value for PtTFP may thus partly reflect a larger portion of the emission band lying outside the visible range.

$$
\text { (Insert Fig. } 8 \text { here please) }
$$

Electroluminescence spectra, reported in Figure 8, show the red emission of PtTFP peaking at $668 \mathrm{~nm}$. The emission is red at voltages $<16 \mathrm{~V}$. At higher voltages, the red emission of the phosphor is accompanied by violet emission (400-450 nm) from the TPD host. The violet/red ratio increases with voltage, as a result of incomplete energy transfer from the host to the guest under these conditions. Increasing electric field reduces the charge recombination zone width, narrowing it to being close to the PtTFP:TPD/TAZ interface, under which conditions the exciton density may exceed the collecting capability of the PtTFP molecules. The quantum efficiency roll-off also becomes steeper for voltages $>16 \mathrm{~V}\left(0.4 \mathrm{~mA} / \mathrm{cm}^{2}\right)$, due to this effect adding to the quenching processes mentioned above. The change in the relative amounts of the two emissions with voltage leads to the colour change from red to purple represented in the CIE diagram inset of Figure 8.

\section{Conclusions}

In conclusion the choice of meso-aryl substituents can allow the properties of porphyrins to be optimised for OLEDs. In the present instance, the shorter lifetime of the fluorenyl-substituted complex delays the onset of the high-current roll-off that normally plagues porphyrin-based systems. Moreover, these new fluorenyl-appended compounds constitute interesting building blocks to access new emissive materials. Based on our recent results of anodic electropolymerisation of platinum porphyrin complexes, ${ }^{34}$ we expect to be able to obtain new red emissive polymeric materials by control of the monomers before assembling, for photonic materials applications.

\section{Experimental section}




\section{General}

All reactions were performed under an atmosphere of argon with magnetic stirring. Solvents were distilled from the appropriate drying agent prior to use, $\mathrm{CH}_{2} \mathrm{Cl}_{2}$ from $\mathrm{CaH}_{2}, \mathrm{CHCl}_{3}$ from $\mathrm{P}_{2} \mathrm{O}_{5}$ and all other solvents were HPLC grade. 5,10,15,20-Meso-tetrakis(fluoren-2-yl)porphyrin (TFP) was prepared as described in our earlier report. ${ }^{13}$ The platinum(II) ${ }^{35}$ and palladium(II) ${ }^{36}$ complexes of TPP were prepared as described previously by others. All reactions were monitored by thin layer chromatography (TLC) with Merck pre-coated aluminium foil sheets (Silica gel 60 with fluorescent indicator $\mathrm{UV}_{254}$ ). Compounds were visualized with ultra-violet light at 254 and $365 \mathrm{~nm}$. Column chromatography was carried out using silica gel from Merck (0.063-0.200 mm). NMR spectra in $\mathrm{CDCl}_{3}$ were recorded using a Bruker 200 DPX spectrometer; chemical shifts are referenced to internal tetramethylsilane (TMS) and coupling constants are in Hertz.

\section{Synthesis of metalloporphyrins (Scheme 1)}

\section{(Insert Scheme 1 here please)}

5,10,15,20-meso-tetrakis(fluoren-2-yl)porphyrinato platinum(II) (PtTFP) was prepared by an adaptation of the procedure used for the Pt(II) complex of TPP. ${ }^{35}$ A suspension of $\mathrm{PtCl}_{2}(0.17 \mathrm{~g}, 0.64 \mathrm{mmol})$ in benzonitrile $(20 \mathrm{~mL})$ was pre-heated at $100^{\circ} \mathrm{C}$ for $1 \mathrm{~h}$ under an argon atmosphere. Free-base porphyrin TFP $(0.15 \mathrm{~g}, 0.155 \mathrm{mmol})$ was added and the mixture refluxed for $7 \mathrm{~h}$, the progress of the reaction being monitored by TLC. The solvent was then removed by vacuum distillation, and the residue purified by chromatography (silica gel, dichloromethane/pentane $=10 / 1$ ) to give the desired product as a reddish-purple solid $(120 \mathrm{mg}, 67 \%)$. The hydrogen and carbon atom-labeling scheme for the porphyrin ligand is shown in scheme 2. ${ }^{1} \mathbf{H}$ NMR (CDCl 3,200 MHz, ppm): $\delta 8.88\left(\mathrm{~s}, 8 \mathrm{H}\right.$, pyrrol), $8.36\left(\mathrm{~s}, 4 \mathrm{H}, \mathrm{H}_{\mathrm{D}}\right), 8.19\left(\mathrm{~d},{ }^{3} \mathrm{~J}_{\mathrm{HH}}=8.2,4 \mathrm{H}_{,} \mathrm{H}_{\mathrm{B}}\right), 8.08\left(\mathrm{~d},{ }^{3} \mathrm{~J}_{\mathrm{HH}}=8.2,4 \mathrm{H}, \mathrm{H}_{\mathrm{A}^{\prime}}\right), 7.84(\mathrm{~d}$, $\left.{ }^{3} \mathrm{~J}_{\mathrm{HH}}=6.6,4 \mathrm{H}, \mathrm{H}_{\mathrm{A}}\right), 7.74\left(\mathrm{~m}, 4 \mathrm{H}, \mathrm{H}_{\mathrm{D}}\right), 7.53-7.46\left(\mathrm{~m}, 8 \mathrm{H}, \mathrm{H}_{\mathrm{B}}\right.$ and $\mathrm{H}_{\mathrm{C}}$ ), $4.23\left(\mathrm{~s}, 8 \mathrm{H}, \mathrm{H}_{\mathrm{E}}\right)$. UV-visible (in $\left.\mathbf{C H}_{2} \mathbf{C l}_{2}\right): 266 \mathrm{~nm}\left(\mathrm{fluorene}, \varepsilon_{266}=80920\right), 409$ $\mathrm{nm}$ (Soret band, $\left.\varepsilon_{409}=315800\right), 512 \mathrm{~nm}\left(\mathrm{Q}\right.$ band, $\varepsilon_{512}=28$ 076), $541 \mathrm{~nm}\left(\mathrm{Q}\right.$ band, $\left.\varepsilon_{540}=4532\right)$. Analysis: calcd for $\mathrm{C}_{72} \mathrm{H}_{44} \mathrm{~N}_{4} \mathrm{Pt} .1 / 2 \mathrm{CHCl}$ : C, 71.38 ; $\mathrm{H}, 3.68$; N, 4.59 found C, 71.57; H, 3.73; N, 4.39. MS (Maldi-TOF): calcd for $\mathrm{C}_{72} \mathrm{H}_{44} \mathrm{~N}_{4} \mathrm{Pt}$ : 1159.320 [M] $]^{+}$, found:1160.481 [MH] ${ }^{+}$. 
5,10,15,20-meso-tetrakis(fluoren-2-yl)porphyrinato palladium(II) (PdTFP) was prepared in a similar manner to the Pt(II) complex. Thus, a suspension of $\mathrm{PdCl}_{2}(0.077 \mathrm{~g}, 0.43 \mathrm{mmol})$ in benzonitrile $(10 \mathrm{~mL})$ was pre-heated at $100^{\circ} \mathrm{C}$ for $1 \mathrm{~h}$ under an argon atmosphere, followed by addition of free-base porphyrin TFP $(0.10 \mathrm{~g}, 0.104 \mathrm{mmol})$. The mixture was heated for a further $3 \mathrm{~h}$, after which TLC revealed complete consumption of the starting material. After removal of solvent by vacuum distillation, the crude product was purified by chromatography (silica gel, dichloromethane/pentane $=1 / 1)$ to give the desired product as a reddish-purple solid $(43 \mathrm{mg}, 40 \%)$. The hydrogen and carbon atom-labeling scheme for the porphyrin ligand is shown in scheme 2. ${ }^{\mathbf{1}} \mathbf{H} \mathbf{N M R}\left(\mathbf{C D C l}_{\mathbf{3}}, \mathbf{2 0 0} \mathbf{M H z}, \mathbf{p p m}\right): 8.93(\mathrm{~s}, 8 \mathrm{H}$, pyrrol$), 8.38\left(\mathrm{~s}, 4 \mathrm{H}, \mathrm{H}_{\mathrm{D}}\right), 8.23\left(\mathrm{~d},{ }^{3} \mathbf{J}_{\mathrm{HH}}=8.2,4 \mathrm{H}\right.$, $\left.\mathrm{H}_{\mathrm{B}}\right), 8.19\left(\mathrm{~d},{ }^{3} \mathrm{~J}_{\mathrm{HH}}=8.2,4 \mathrm{H}, \mathrm{H}_{\mathrm{A}^{\prime}}\right), 8.08\left(\mathrm{~d},{ }^{3} \mathrm{~J}_{\mathrm{HH}}=6.6,4 \mathrm{H}, \mathrm{H}_{\mathrm{A}}\right), 7.73\left(\mathrm{~d},{ }^{3} \mathrm{~J}_{\mathrm{HH}}=6.6,4 \mathrm{H}, \mathrm{H}_{\mathrm{D}}\right), 7.56-7.46\left(\mathrm{~m}, 8 \mathrm{H}, \mathrm{H}_{\mathrm{B}}\right.$ and $\left.\mathrm{H}_{\mathrm{C}}\right), 4.23\left(\mathrm{~s}, 8 \mathrm{H}, \mathrm{H}_{\mathrm{E}}\right) . \mathbf{U V}-$ visible (in $\mathbf{C H}_{2} \mathbf{C l}_{2}$ ): $262 \mathrm{~nm}$ (fluorene, $\varepsilon_{262}=68515$ ), $423 \mathrm{~nm}$ (Soret band, $\varepsilon_{423}=190284$ ), $526 \mathrm{~nm}\left(\mathrm{Q}\right.$ band, $\left.\varepsilon_{526}=16658\right), 560 \mathrm{~nm}\left(\mathrm{Q}\right.$ band, $\varepsilon_{560}=3$ 244). Analysis: calcd for $\mathrm{C}_{72} \mathrm{H}_{44} \mathrm{~N}_{4} \mathrm{Pd} . \mathrm{CHCl}_{3}$ : C, 73.62; H, 3.81; N, 4.70 found C, 73.80; H, 3.49; N, 4.81 . MS (Maldi-TOF): calcd for $\mathrm{C}_{72} \mathrm{H}_{44} \mathrm{~N}_{4} \mathrm{Pd}$ : $1070.260[\mathrm{M}]$, found: $1071.084[\mathrm{MH}]^{+}$.

(Insert Scheme 2 here please)

\section{Photophysical properties}

Absorption spectra were measured on a Biotek Instruments XS spectrometer, using quartz cuvettes of $1 \mathrm{~cm}$ pathlength. Steady-state luminescence spectra in solution were measured using a Jobin Yvon FluoroMax-2 spectrofluorimeter, fitted with a red-sensitive Hamamatsu R928 photomultiplier tube; the spectra shown are corrected for the wavelength dependence of the detector, and the quoted emission maxima refer to the values after correction. Samples for emission measurements were contained within quartz cuvettes of $1 \mathrm{~cm}$ pathlength modified with appropriate glassware to allow connection to a high-vacuum line. Degassing was achieved via a minimum of three freeze-pump-thaw cycles whilst connected to the vacuum manifold; final vapour pressure at $77 \mathrm{~K}$ was $<5 \times 10^{-2} \mathrm{mbar}$, as monitored using a Pirani gauge. Luminescence quantum yields were determined using $\left[\mathrm{Ru}(\mathrm{bpy})_{3}\right] \mathrm{Cl}_{2}$ in degassed aqueous solution as the standard $\left(\phi=0.042^{37}\right)$; estimated uncertainty in $\Phi$ is $\pm 20 \%$ or better. 
The luminescence lifetimes of the complexes were measured by multichannel scaling, following excitation with a $\mu$ s-pulsed xenon lamp. The emitted light was detected at $90^{\circ}$ using a Peltier-cooled R928 PMT after passage through a monochromator. The estimated uncertainty in the quoted lifetimes is $\pm 10 \%$ or better. Bimolecular rate constants for quenching by molecular oxygen, $k_{\mathrm{Q}}$, were determined from the lifetimes in degassed and


obtained in $4 \mathrm{~mm}$ diameter tubes using a liquid nitrogen dewar.

\section{OLED device fabrication}

The device for electroluminescence experiments was a simple double-layer OLED (scheme 3). The first layer, $70 \mathrm{~nm}$ thick and acting as hole transport and emitting layer, was spin-cast on ITO glass, cleaned with standard procedure, from a dichloromethane solution of bisphenol-A-polycarbonate (PC), $N, N$ '-diphenyl- $N, N^{\prime}$-bis(3-methylphenyl-(1,1'-biphenyl)-4,4'-diamine (TPD), and PtTFP with their relative weight proportion of 20:75:5. Then, a 3,5bis-(4-tert-butyl-phenyl)-4-phenyl-4H-[1,2,4]triazole (TAZ) layer (thickness $=60 \mathrm{~nm}$ ) to confine excitons and holes in the emitting layer, and a LiF film (thickness $=0.5 \mathrm{~nm}$ ) with an $\mathrm{Al}$ cap as the cathode (thickness $=100 \mathrm{~nm}$ ), were laid down by vacuum sublimation at $\sim 10^{-6} \mathrm{hPa}$. Each layer thickness was measured with a Tencor Alpha Step 200 profilometer. Compounds were purchased from Aldrich (TPD and TAZ), and from Polysciences Inc. (PC) and used as supplied.

Solid state absorption and emission measurements were carried out using a Perkin Elmer Lambda 9 UV/Vis/NIR absorption spectrometer and a SPEX Florolog emission spectrometer. The current-voltage characteristics were measured with a Keithley Source-Measure unit, model 236, under continuous operation mode, while the light output power was measured with an EG\&G power meter. Electroluminescence spectra were obtained with a StellarNet spectroradiometer. All measurements were carried out at room temperature under argon atmosphere and were reproduced for many runs, excluding any irreversible chemical and morphological changes in the devices.

(Insert Scheme 3 here please)

\section{Acknowledgements}


The authors are grateful to S. Sinbandhit (CRMPO), G. Simonneaux and P. Le Maux (ICMV-UMR 6226) for their technical assistance and helpful discussions.

\section{References}

J. H. Burroughes, D. C. Bradley, A. B. Brown, R. N. Marks, K. Mackey, R. H. Friend, P. L. Bum, and A. B. Holmes, Nature, $1990,347,539$. J. R. Sheat, H. Antoniadis, M. Hueschen, W. Leonard, J. Miller, R. Moon, D. Roitman, and A. Stocking, Science, $1996,273,884$.

H. Nakamura, C. Hosokawa, and T. Kusumoto, in : Inorganic and organic Electroluminescence/EL 96,R. H. Mauch, H. E. Gumlich (Eds), Wissenschaft und Technik, Berlin, 1996, 65.

W.-Y. Wong, Coord. Chem. Rev., 2005, 249, 971.

W.-Y. Wong and C.-L. Ho, J. Mater. Chem., 2009, 19, 4457.

W.-Y. Wong and C.-L. Ho, Coord. Chem. Rev., 2009, 253, 1709.

J. Rault-Berthelot, Electrochemistry, 2003, 10, 265.

X. H. Zang, Z. Y. Xie, F. P. Wu, L. L. Zhou, O. Y. Wong, C. S. Lee, H. L. Kwong, S. T. Lee, and S. K. Wu, Chem. Phys. Lett., $2003,382,561$.

M. A. Baldo, D. F. O'Brien, Y. You, A. Shoustikov, S. Sibley, M. E. Thompson, and S. R. Forrest, Nature, 1998, 395, 151

T. Virgili, D. G. Lidzey, and D. C. Bradley, Synth. Metals, 2000, 111-112, 203.

B. Li, J. Li, Y. Fu, and Z. Bo, J. Am. Chem. Soc., 2004, 126, 3430.

B. Li, X. Xu, M. Sun, Y. Fu, G. Yu, Y. Liu, and Z. Bo, Macromolecules, 2006, 39, 456.

C. Paul-Roth, J. Rault-Berthelot, and G. Simonneaux, Tetrahedron, 2004, 60, 12169.

C. Poriel, Y. Ferrand, P. Le Maux, C. Paul-Roth, G. Simonneaux, and J. Rault-Berthelot, J. Electroanal. Chem., $2005,583,92$.

G. Simonneaux, E. Galardon, C. Paul-Roth, M. Gulea, and S. Masson, J. Organomet. Chem., 2001, 617-618, 360.

C. Poriel, Y. Ferrand, P. Le Maux, C. Paul, J. Rault-Berthelot, and G. Simonneaux, Chem. Commun., 2003, 18, 2308.

C. O. Paul-Roth and G. Simonneaux C.R. Acad. Sci., Ser. IIb: Chim., 2006, 9, 1277.

C. O. Paul-Roth and G. Simonneaux, Tetrahedron Lett., 2006, 47, 3275.

C. Paul-Roth, G. Williams, J. Letessier, and G. Simonneaux Tetrahedron Lett., 2007, 48, 4317.

S. Drouet, C. Paul-Roth, and G. Simonneaux, Tetrahedron, 2009, 65, 2975.

S. Drouet and C. O. Paul-Roth, Tetrahedron, 2009, 65, 10693.

Highly Efficient OLEDs with Phosphorescent Materials, ed. H. Yersin, Wiley-VCH, Berlin, 2007.

V. A. Montes, C. Prez-Bolvar, N. Agarwal, J. Shinar, and P. Anzenbacher, J. Am. Chem. Soc., 2006, 128, 12436.

S. Fu, X. Zhu, G. Zhou, W.-Y. Wong, C. Ye, W.-K. Wong, and Z. Li, Eur. J. Inorg. Chem., 2007, 2004.

L. R. Milgrom, Polyhedron, 1984, 3, 879. 
A. K. Wertsching, A. S. Koch, and S. G. DiMagno, J. Am. Chem. Soc., 2001, 123, 3932.

Y.-H. Zhang, W.-J. Ruan, Z.-Y. Li, Y. Wu, and J.-Y. Zheng, Chem. Phys. Let., 2005, 315, 201.

F. Niedermair, S. M. Borisov, G. Zenkl, O. T. Hofmann, H. Weber, R. Saf, and I. Klimant, Inorg. Chem., 2010, DOI: 10.1021/ic100955z.

M. Cocchi, V. Fattori, C. Sabatini, P. Di Marco, M. Maestri, and J. Kalinowski, Applied Physics Letters, $2004, \mathbf{8 4 ,} 1052$.

J. Kalinowski, W. Stampor, M. Cocchi, D. Virgili, V. Fattori, and P. Di Marco, Chemical Physics Letters, 2004, $297,39$.

J. Kalinowski, W. Stampor, J. Szmytkowski, D. Virgili, M. Cocchi, V. Fattori, and C. Sabatini, Physical Review B, $2006,74,85316$.

D. F. O'Brien, M. A. Baldo, M. E. Thompson, and S. R. Forrest, Applied Physics Letters, 1999, 74, 442.

J. Kalinowski, W. Stampor, J. Szmytkowski, M. Cocchi, D. Virgili, V. Fattori, and P. Di Marco, The Journal of Chemical Physics, 2005, 122, 154710.

34 S. Drouet, S. Ballut, J. Rault-Berthelot, P. Turban, and C. Paul-Roth, Thin Solid Films, 2009, 517, 5474.

L. M. Mink, M. L. Neitzel, L. M. Bellomy, R. E. Falvo, R. K. Boggess, B. T. Trainum, and P. Yeaman, Polyhedron, $1997,16,2809$.

J. W. Buchler, Porphyrins and Metalloporphyrins; Smith, K. Ed.; Elsevier Scientific Publishing Co. : Amsterdam, $1975,157$.

J. Van Houten and R. J. Watts, J. Am. Chem. Soc., 1976, 98, 4853.

38 S. L. Murov, I. Carmichael, and G. L. Hug, Handbook of Photochemistry, 2nd ed., Marcel Dekker: New York, 1993. 


\section{Schemes and Figures Captions}

Table 1 Absorption and emission data for the platinum(II) and palladium(II) porphyrins in $\mathrm{CH}_{2} \mathrm{Cl}_{2}$ at $298 \mathrm{~K}$ and in diethyl ether / isopentane / ethanol $(2: 2: 1 \mathrm{v} / \mathrm{v})$ at $77 \mathrm{~K}$

Fig. 1 UV-visible absorption spectra of the platinum(II) complexes of TFP and TPP in $\mathrm{CH}_{2} \mathrm{Cl}_{2}$ solution at $298 \pm 3 \mathrm{~K}$.

Fig. 2 Photoluminescence spectra of the platinum(II) complexes of TFP and TPP in degassed $\mathrm{CH}_{2} \mathrm{Cl}_{2}$ at $298 \pm 3 \mathrm{~K}$.

Fig. 3 Photoluminescence spectra of the platinum(II) complexes of TFP and TPP in diethyl ether / isopentane / ethanol (2:2:1, v/v) at 77 K.

Fig. 4 UV-visible absorption spectra of the palladium(II) complexes of TFP and TPP in $\mathrm{CH}_{2} \mathrm{Cl}_{2}$ solution at $298 \pm 3 \mathrm{~K}$.

Fig. 5 Photoluminescence spectra of the palladium(II) complexes of TFP and TPP in $\mathrm{CH}_{2} \mathrm{Cl}_{2}$ at $298 \mathrm{~K}$ (solid lines) and in diethyl ether / isopentane / ethanol $(2: 2: 1, \mathrm{v} / \mathrm{v})$ at $77 \mathrm{~K}$ (dashed lines).

Fig. 6 Excitation spectrum $\left(\lambda_{\mathrm{em}}=668 \mathrm{~nm}\right.$, solid line $)$ and emission spectrum $\left(\lambda_{\mathrm{ex}}=350 \mathrm{~nm}\right.$, dashed line $)$ of a PtTFP:TPD [5:95 wt ratio] film, $70 \mathrm{~nm}$ thick.

Fig. 7 External quantum efficiency (circles) and luminous efficiency (squares) as a function of current density.

Fig. 8 Electroluminescence spectra at different applied voltages. Inset: corresponding CIE coordinates; CIE of pure TPD and pure PtTFP emissions are also reported. 
Scheme 1 Synthesis of metalloporphyrins.

Scheme 2 The hydrogen and carbon atom-labeling scheme for the porphyrin ligand.

Scheme 3 The device for electroluminescence experiments was a simple double-layer OLED. 
Table 1 Absorption and emission data for the platinum(II) and palladium(II) porphyrins in $\mathrm{CH}_{2} \mathrm{Cl}_{2}$ at $298 \mathrm{~K}_{\text {and in diethyl ether / }}$ isopentane / ethanol $(2: 2: 1 \mathrm{v} / \mathrm{v})$ at $77 \mathrm{~K}$

\begin{tabular}{|c|c|c|c|c|c|c|c|c|c|}
\hline & $\begin{array}{c}\lambda_{\max }^{\text {abs }} / \mathrm{nm}^{(a)} \\
\text { Soret; Q }\end{array}$ & $\begin{array}{c}\lambda_{\max }^{\mathrm{em}} / \mathrm{nm} \\
298 \mathrm{~K}\end{array}$ & $\begin{array}{l}\tau / \mu \mathrm{s} \\
298 \mathrm{~K}\end{array}$ & $\begin{array}{c}\Phi_{\text {lum }} \times 10^{2(b)} \\
298 \mathrm{~K}\end{array}$ & $\begin{array}{c}k_{\mathrm{r}} / \mathrm{s}^{-1} \\
\text { (c) }\end{array}$ & $\begin{array}{c}\sum k_{\mathrm{nr}} / \\
10^{3} \mathrm{~s}^{-1(c)}\end{array}$ & $\begin{array}{c}k_{\mathrm{Q}}^{\mathrm{O} 2} / \\
10^{8} \mathrm{M}^{-1} \mathrm{~s}^{-1(d)}\end{array}$ & $\begin{array}{c}\lambda_{\max }^{\mathrm{em}} / \mathrm{nm} \\
77 \mathrm{~K}\end{array}$ & $\begin{array}{l}\tau / \mu \mathrm{s} \\
77 \mathrm{~K}\end{array}$ \\
\hline PtTPP & $400 ; \quad 508,538$ & 668,734 & 59 & 4.6 & 780 & 16.2 & 6.8 & 655,728 & 132 \\
\hline PtTFP & $\begin{array}{c}409 ; 512, \\
540(\mathrm{sh})\end{array}$ & 679,741 & 22 & 2.0 & 910 & 44.5 & 5.9 & 661,730 & 102 \\
\hline PdTPP & $415 ; 522,553$ & 705,776 & 443 & 1.2 & 27 & 2.27 & 3.1 & 685,763 & 1380 \\
\hline PdTFP & $423 ; 526,560$ & 715,785 & 248 & 0.9 & 36 & 4.00 & 3.1 & 693,771 & 1290 \\
\hline
\end{tabular}

(a) The wavelength of the Soret band is given first, followed by the wavelengths of the two observed Q bands.

(b) Quantum yields were measured using $\left[\mathrm{Ru}(\mathrm{bpy})_{3}\right] \mathrm{Cl}_{2}$ in $\mathrm{H}_{2} \mathrm{O}$ as the standard, as described in the experimental section.

(c) $k_{\mathrm{r}}$ and $\Sigma k_{\mathrm{nr}}$ are the radiative and non-radiative decay rate constants, calculated from $\Phi_{\text {lum }}$ and $\tau$ as described in the text.

(d) $\mathrm{k}_{\mathrm{Q}}{ }^{\mathrm{O} 2}$ is the bimolecular rate constant for quenching by molecular oxygen in solution. 


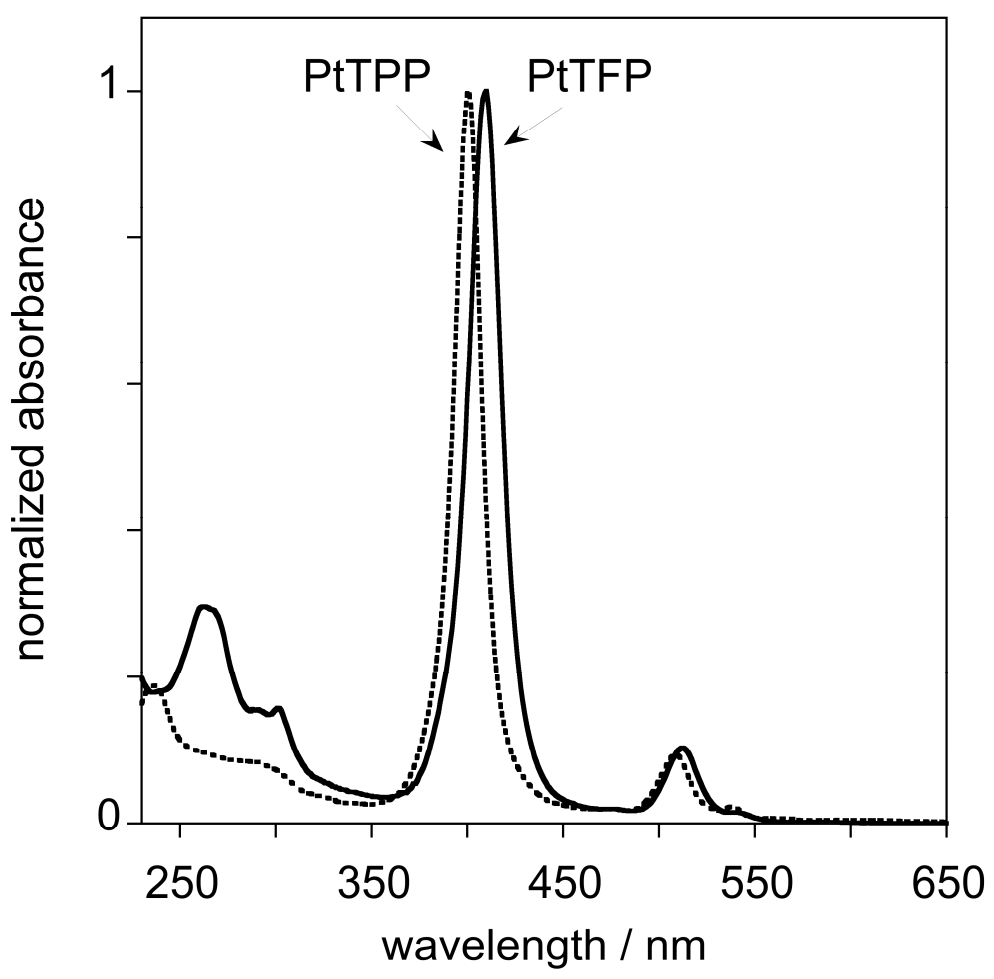

Fig. 1 UV-visible absorption spectra of the platinum(II) complexes of TFP and TPP in $\mathrm{CH}_{2} \mathrm{Cl}_{2}$ solution at $298 \pm 3 \mathrm{~K}$.

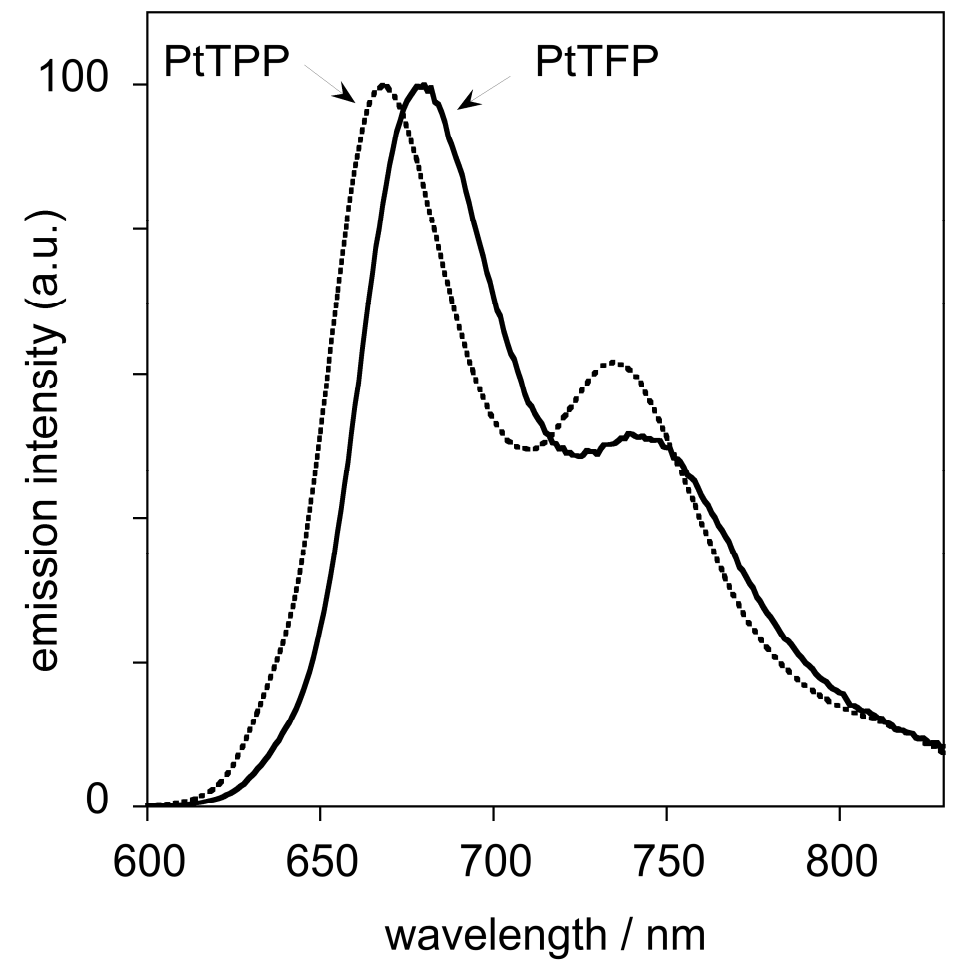

Fig. 2 Photoluminescence spectra of the platinum(II) complexes of TFP and TPP in degassed $\mathrm{CH}_{2} \mathrm{Cl}_{2}$ at $298 \pm 3 \mathrm{~K}$. 


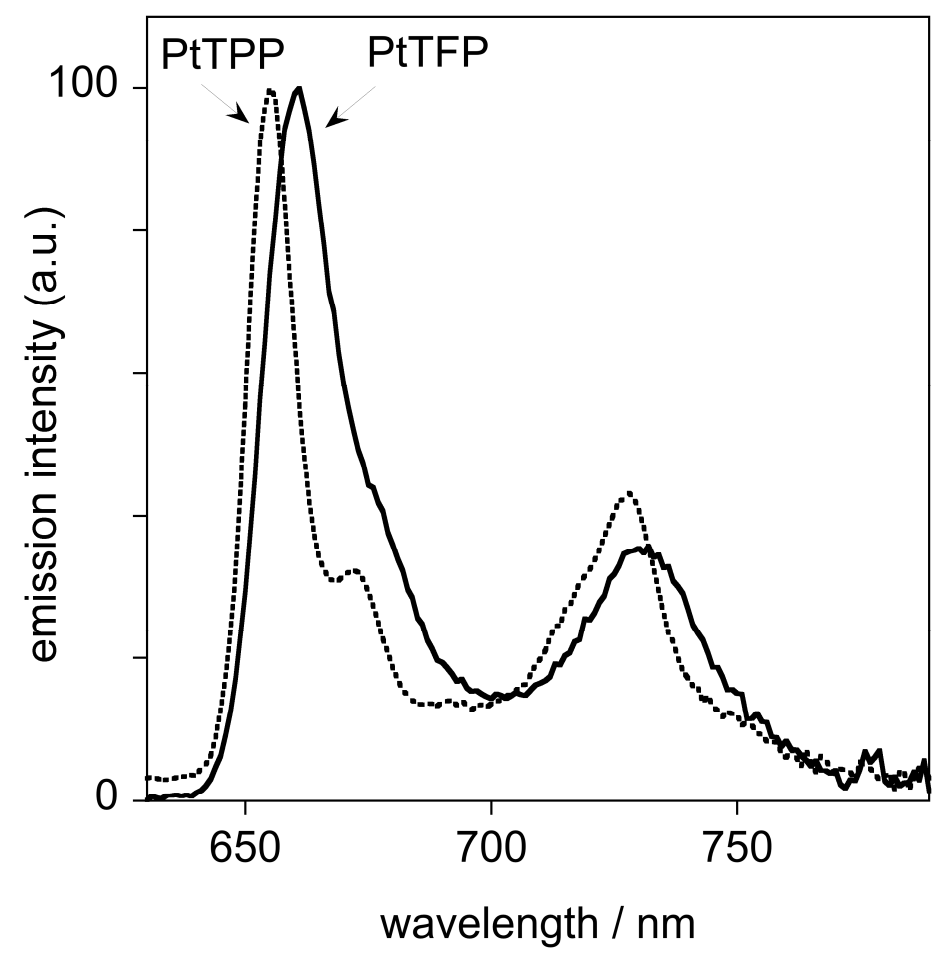

Fig. 3 Photoluminescence spectra of the platinum(II) complexes of TFP and TPP in diethyl ether / isopentane / ethanol $(2: 2: 1, \mathrm{v} / \mathrm{v})$ at $77 \mathrm{~K}$.

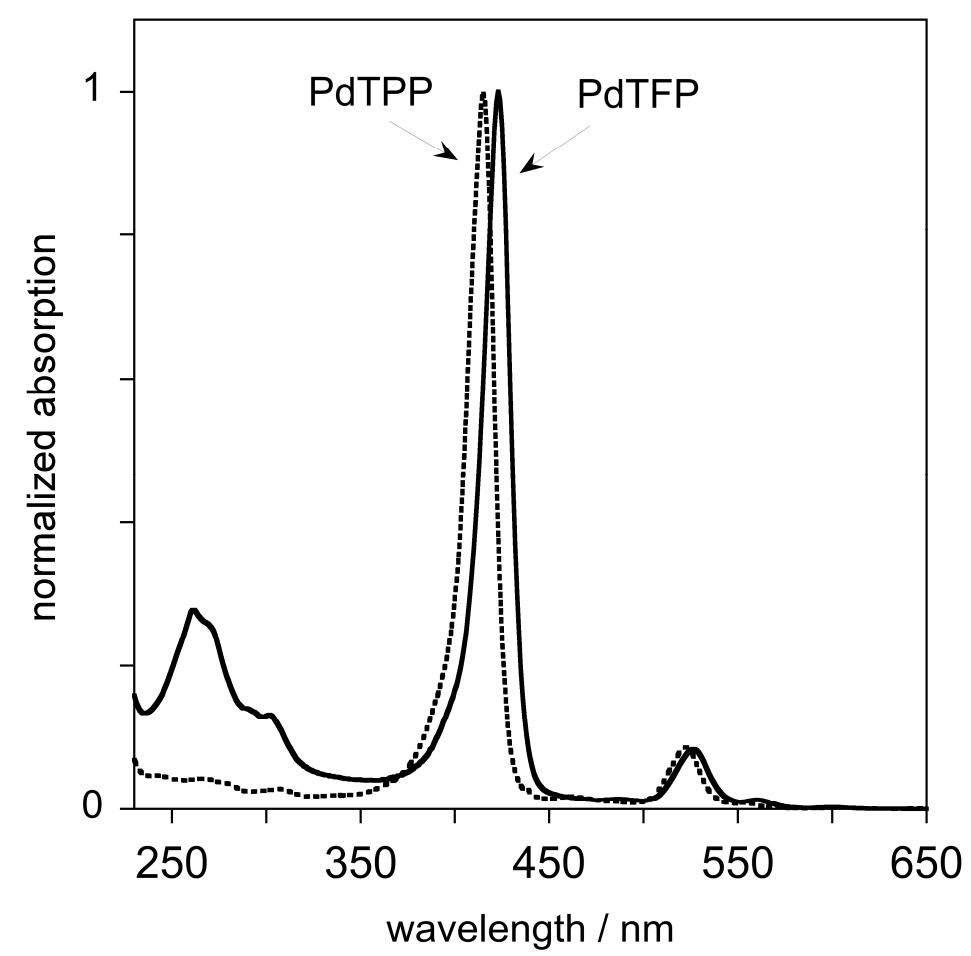

Fig. $4 \mathrm{UV}$-visible absorption spectra of the palladium(II) complexes of TFP and TPP in $\mathrm{CH}_{2} \mathrm{Cl}_{2}$ solution at $298 \pm 3 \mathrm{~K}$. 


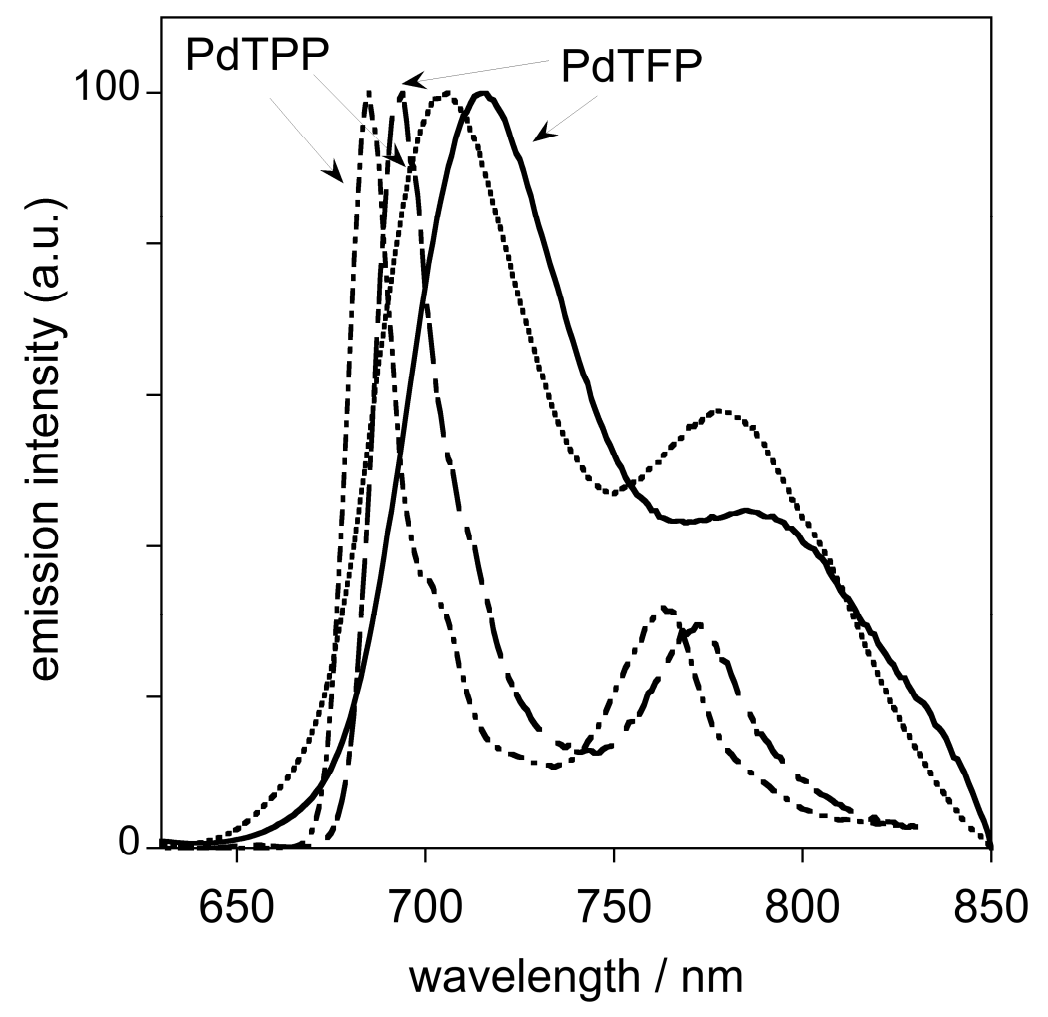

Fig. 5 Photoluminescence spectra of the palladium(II) complexes of TFP and TPP in $\mathrm{CH}_{2} \mathrm{Cl}_{2}$ at 298 $\mathrm{K}$ (solid lines) and in diethyl ether / isopentane / ethanol (2:2:1, v/v) at $77 \mathrm{~K}$ (dashed lines).

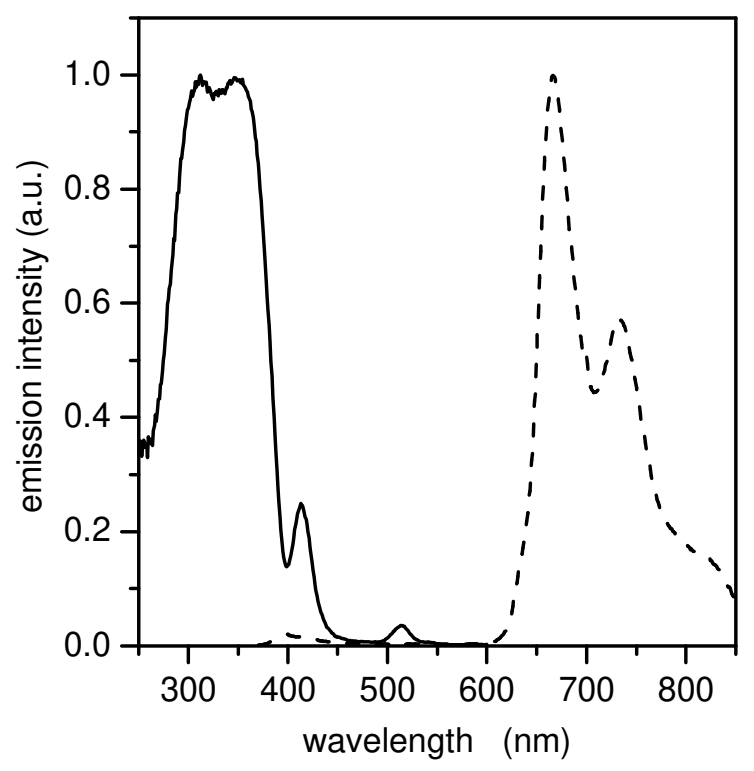

Fig. 6 Excitation spectrum $\left(\lambda_{\mathrm{em}}=668 \mathrm{~nm}\right.$, solid line $)$ and emission spectrum $\left(\lambda_{\mathrm{ex}}=350 \mathrm{~nm}\right.$, dashed line) of a PtTFP:TPD [5:95 wt ratio] film, $70 \mathrm{~nm}$ thick. 


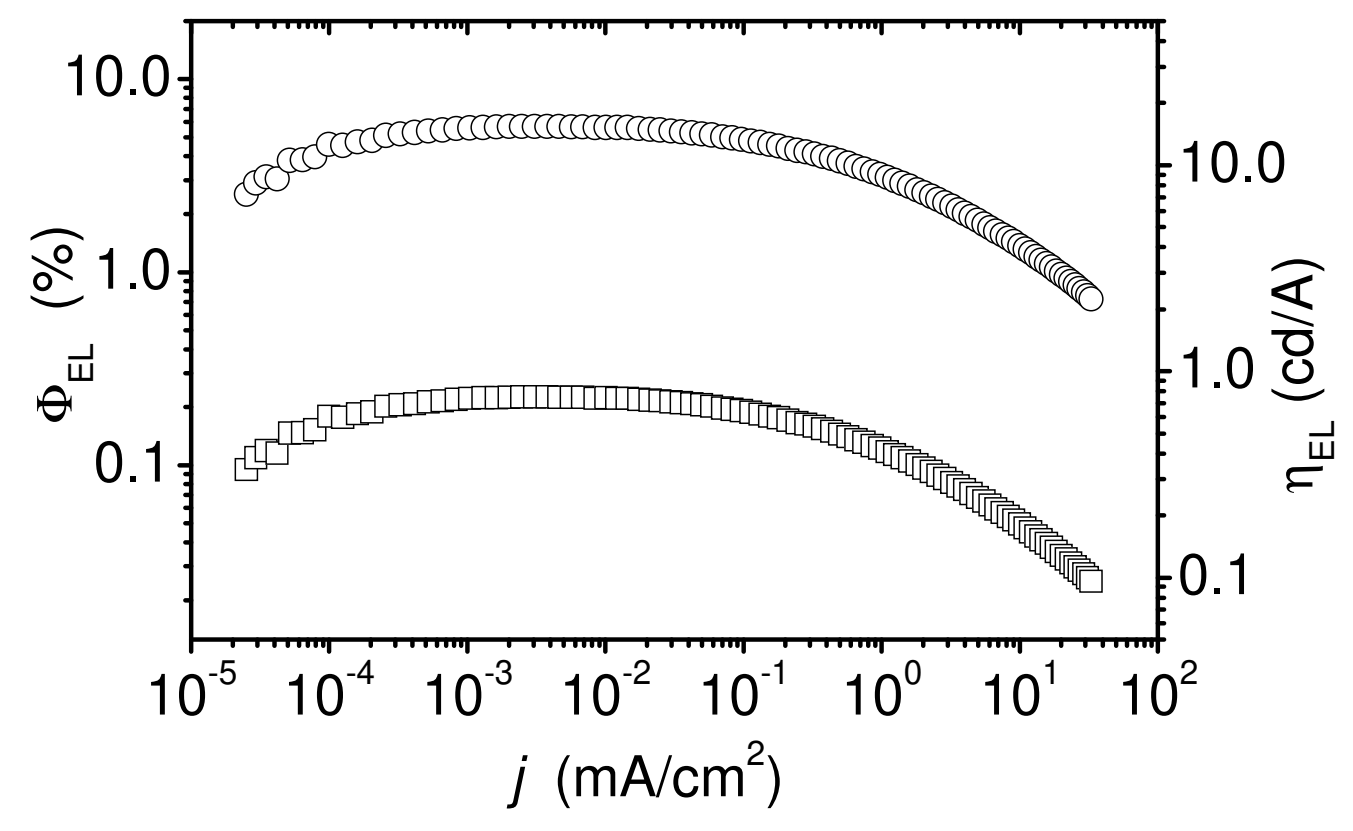

Fig. 7 External quantum efficiency (circles) and luminous efficiency (squares) as a function of current density.



Fig. 8 Electroluminescence spectra at different applied voltages. Inset: corresponding CIE coordinates; CIE of pure TPD and pure PtTFP emissions are also reported. 


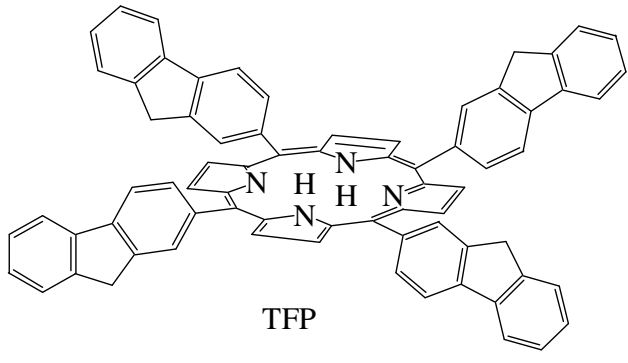

Scheme 1 Synthesis of metalloporphyrins.
$\mathrm{MCl}_{2}$

reflux in benzonitrile

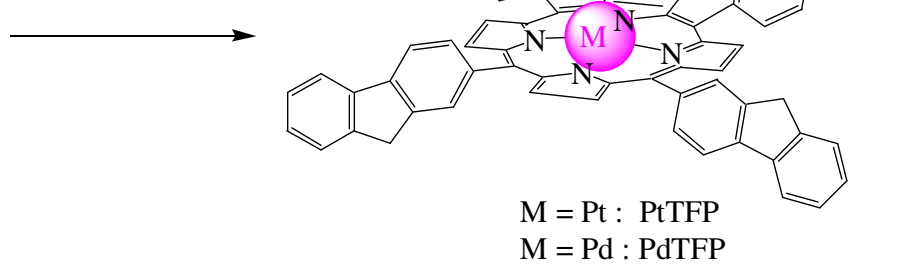

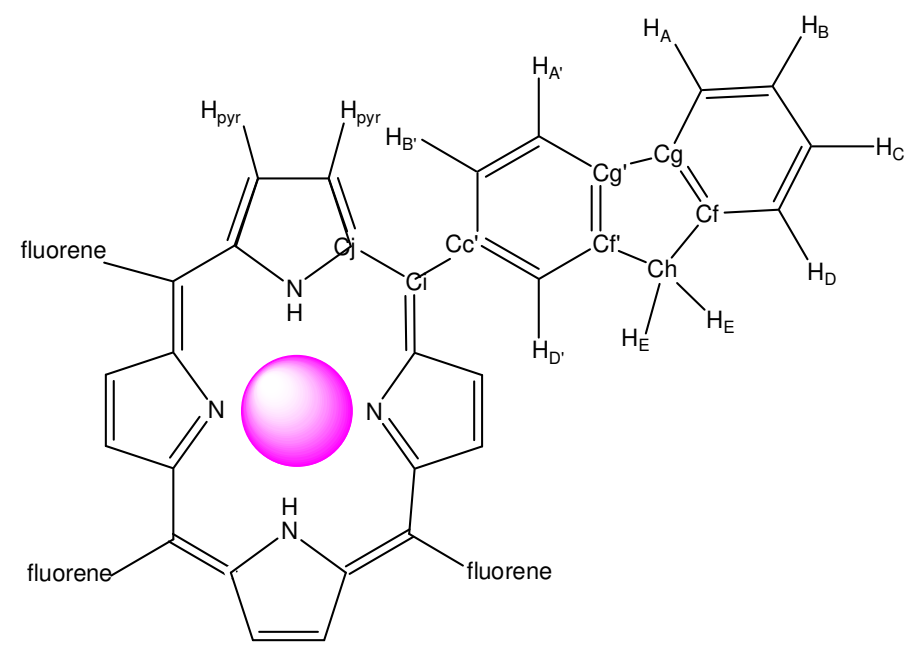

Scheme 2 The hydrogen and carbon atom-labeling scheme for the porphyrin ligand . 


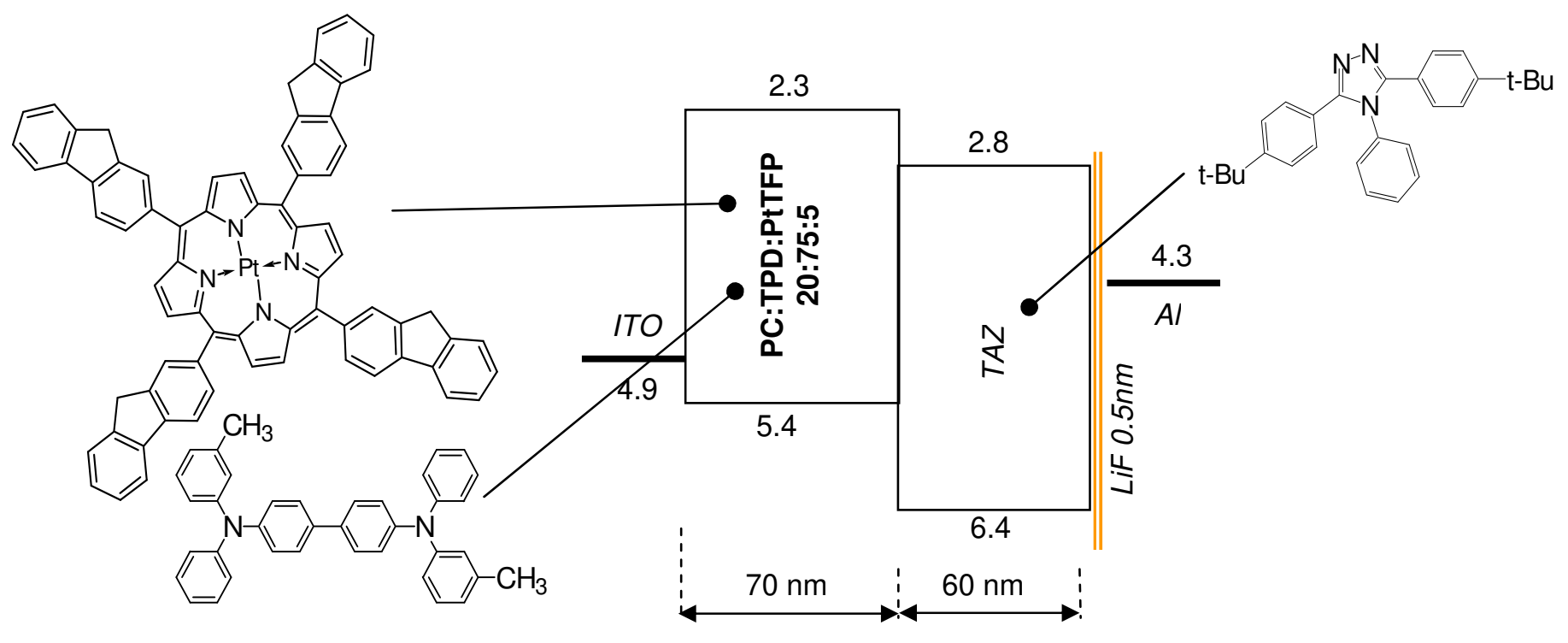

Scheme 3 The device for electroluminescence experiments was a simple double-layer OLED. 